\title{
The Liver in COVID-19-Related Death: Protagonist or Innocent Bystander?
}

\author{
Grégory Schmit $^{a, b}$ Julie Lelotte ${ }^{b, c}$ Jessica Vanhaebost ${ }^{a, b} \quad$ Yves Horsmans $^{b, d}$ \\ Mieke Van Bockstal b, c Pamela Baldin b, c \\ ${ }^{a}$ Center of Forensic Medicine, Department of Pathology, Cliniques Universitaires Saint-Luc, Brussels, Belgium; \\ ${ }^{b}$ Institut de Recherche Expérimentale et Clinique, UCLouvain, Brussels, Belgium; 'Department of Pathology, \\ Cliniques Universitaires Saint-Luc, Brussels, Belgium; ${ }^{d}$ Department of Hepato-Gastro-Enterology, Cliniques \\ Universitaires Saint-Luc, Brussels, Belgium
}

\section{Keywords}

Liver · COVID-19 · Pathology · Autopsy · SARS-CoV-2

\begin{abstract}
Introduction: The coronavirus disease 2019 (COVID-19) infection, caused by severe acute respiratory syndrome corona virus 2 (SARS-CoV-2), involves several organs through participation of angiotensin-conversion enzyme 2 (ACE2) receptors. The presence of ACE2 receptors in the liver renders this organ a potential target for the novel coronavirus. Methods: We performed 14 complete autopsies of patients infected with SARS-CoV-2. In each case we stained liver tissue sections with haematoxylin/eosin, Masson blue trichrome stain, periodic acid-Schiff (PAS), Perls, and performed cytokeratin-7 (CK7) immunochemistry. Results: Macroscopically, livers were pale and yellowish in 8 of 14 (57\%) patients, and had a nutmeg appearance in the other 6 cases (42\%). Histologically, centrolobular necrosis was observed in 12 cases (86\%), and was associated with discreet to moderate lobular or portal inflammation. Steatosis was seen in 8 cases (57\%), but fibrosis was rare. Cholestasis and discrete bile duct proliferation was observed in 5 cases (36\%). Discussion/Conclusion: The main histological changes can be explained by the hy-
\end{abstract}

poxic status as a result of severe hypoxemic pneumonia leading to death. Drug toxicity may also play a role in certain cases. Other histological changes may be explained by previous hepatic conditions or underlying hepatic diseases. We concluded that COVID-19 infection was not associated with a specific histopathological pattern of the liver.

(c) 2020 S. Karger AG, Basel

\section{Introduction}

The coronavirus 2019 (COVID-19) pandemic, caused by the severe acute respiratory syndrome corona virus 2 (SARS-CoV-2), originated in China in December 2019, and quickly spread throughout the world [1]. Within Europe, the first patients were detected in France and Italy [2]. The Belgian population was severely affected by the virus [3].

From the start of the pandemic, our institution made the decision to systematically perform complete autopsies on patients with a positive polymerase chain reaction (PCR) test for SARS-CoV-2 who died in the intensive care unit. Although autopsies remain the gold standard for determining causes of death [4-6], very few autopsies karger@karger.com

www.karger.com/pat

(C) 2020 S. Karger AG, Base

Karger"
Grégory Schmit

Centre de Médecine Forensique

Cliniques Universitaires Saint-Luc

Avenue Hippocrate, 10, BE-1200 Brussels (Belgium)

gregory.schmit@uclouvain.be 
have been performed in patients with COVID-19, and only a few publications describe complete autopsies [7, 8]. The series sizes of these reports are also generally limited. To our knowledge, only 1 autopsy study of more than 10 cases has been reported [9]. Moreover, the majority of postmortem studies involve so-called "minimally invasive autopsies," using needle biopsies in a limited number of patients [10].

Since the start of the pandemic, numerous studies have described the impact of COVID-19 on different organs. It is obvious that the lungs are the most severely affected organs, and postmortem examinations have revealed several cases of diffuse alveolar damage, often associated with capillary congestion and varying degrees of acute and chronic inflammation and edema of the bronchial mucosa $[11,12]$. The histopathological findings in the lungs often indicate dysfunction of the blood vessels [11]. The kidneys have also been studied in great detail $[13,14]$. Despite perturbations of liver enzymes in COVID19 -positive patients $[15,16]$, there has only been 1 study thus far with a focus on hepatic histopathological changes [17].

In the present study, we report a series of 14 patients deceased in the intensive care unit of our hospital. Each patient tested positive for COVID-19 and a complete autopsy was performed. In this report, we have focused on, and described, the histopathological changes in the liver, although a complete histological study of the different organs was carried out for each autopsy.

\section{Materials and Methods}

\section{Patient Characteristics}

All patients were diagnosed with COVID-19 infection at the Cliniques Universitaires Saint-Luc, Brussels, Belgium. The diagnosis of COVID-19 infection was made by PCR on nasal swabs. Informed consent for the autopsy was obtained from the family members. Details regarding patient history and recent treatment/s were obtained from the treating clinicians, who obtained all data from the electronic patient files. The following data were recorded for this study: patient age at death, all medication used during their stay at the intensive care unit, duration of hospitalization and permanence at the intensive care unit, comorbidities, body mass index (BMI), hepatic enzymes level (gamma glutamyl transferase, aspartate amino transferase, and alanine amino transferase) at the time of admission and death, and the presence of a secondary infection. The delay between death and autopsy was noted in hours.

\section{Autopsies and Histopathological Evaluation}

The autopsies were performed using the "en bloc" sampling technique, as previously described [18]. All autopsies were performed according to the sanitary protection guidelines [19], adapted to the local institutional rules.

The Liver in COVID-19-Related Death
For each autopsy, the liver was weighed and cut into slices of $1 \mathrm{~cm}$ thickness. The macroscopic features were described and included the overall color and presence or absence of masses and nodules. Gallbladders were, if present, incised, emptied, inspected, and sampled. Two liver tissue samples were taken from each lobe, fixed in buffered formalin for 24-48 h and paraffin embedded. In each case, sections were stained with hematoxylin-eosin (HE), Masson blue trichrome stain, Perls iron stain, and periodic acidSchiff (PAS). In addition, CK7 immunohistochemical staining (monoclonal mouse, clone OV-TL12/30, from Dako, dilution $1 / 100$, ultraview DAB detection kit from Ventana) was performed.

All slides were examined by 2 pathologists (P.B. and J.L.) using a dual-head, light microscope.

This study has been approved by the institutional ethics committee (2020/265).

\section{Results}

\section{Clinical Patient Characteristics}

In our institution, 78 patients died from COVID-19 between March 10, 2020 and June 16, 2020. Twenty-three patients died in the intensive care units. Among these 23 patients, only 14 autopsies were performed. For the remaining patients, autopsies were refused by their families, either for religious, philosophical, or psychological reasons.

The patient characteristics are shown in Table 1. The study comprised 10 men and 4 women with a median of 63.2 years (range $50-83$ years), and a median BMI of 32 $\mathrm{kg} / \mathrm{m}^{2}$ (range $21.4-49.8 \mathrm{~kg} / \mathrm{m}^{2}$ ). Eleven patients (78.5\%) were treated with hydroxychloroquine. During hospitalization, only 3 patients $(21.4 \%)$ did not have a secondary bacterial infection, and therefore did not receive antibiotic therapy. The most frequent comorbidities were predominantly vascular (hypertension and heart disease), but also included high BMI or obesity.

One patient (patient 13) was HIV-positive but had an undetectable viral load for several years under triple therapy (darunavir, emtricitabine, tenofovir). One patient (patient 5) presented with non-alcoholic steatohepatitis (NASH), and another (patient 9) had untreated hepatitis $\mathrm{C}$ virus (HCV) infection. Finally, 1 patient (patient 10) was considered cured of COVID-19 and was discharged from intensive care, only to die 2 days later in the setting of acute mesenteric ischemia. He had end-stage renal disease, treated with dialysis.

Only 3 patients (patients 2, 7, and 8) had important elevation of hepatic enzymes at the moment of death. Other patients had normal or slightly elevated hepatic enzymes at the time of admission and death, as shown in Table 2. 
Table 1. Clinical characteristics of a series of 14 patients deceased after COVID-19 infection

\begin{tabular}{|c|c|c|c|c|c|c|c|}
\hline $\begin{array}{l}\text { Patient } \\
\text { No. }\end{array}$ & $\begin{array}{l}\text { Age, } \\
\text { years }\end{array}$ & Sex & $\begin{array}{l}\mathrm{BMI} \\
\mathrm{kg} / \mathrm{m}^{2}\end{array}$ & Main treatment & Secondary infections & $\begin{array}{l}\text { Hospitalization } \\
\text { time, days }\end{array}$ & $\begin{array}{l}\text { Death-to- } \\
\text { autopsy } \\
\text { delay, h }\end{array}$ \\
\hline 2 & 54 & M & 27.0 & $\begin{array}{l}\text { Hydroxychloroquine, ceftazidime, } \\
\text { meropenem }\end{array}$ & Pseudomonas aeruginosa & 17 & 18 \\
\hline 4 & 71 & $\mathrm{~F}$ & 27.2 & Cefuroxime, amiodarone & Escherichia coli & 20 & 4 \\
\hline 5 & 54 & M & 37.8 & Hydroxychloroquine, cefuroxime & Haemophilus & 24 & 8 \\
\hline 6 & 64 & M & 39.8 & Hydroxychloroquine, oxacillin & Staphylococcus aureus & 12 & 17 \\
\hline 7 & 56 & M & 29.8 & Hydroxychloroquine, amoxicillin, ciprofloxacin & S. aureus, Haemophilus & 21 & 73 \\
\hline 11 & 81 & $\mathrm{~F}$ & 27.9 & Hydroxychloroquine, cefuroxime & Haemophilus & 14 & 2.5 \\
\hline 12 & 59 & M & 33.0 & $\begin{array}{l}\text { Hydroxychloroquine, oxacillin, ciprofloxacin, flucloxa- } \\
\text { cillin, ceftazidime, acyclovir, ganciclovir, temocillin, } \\
\text { vancomycin }\end{array}$ & $\begin{array}{l}\text { Enterobacter, HSV1, S. aureus, } \\
\text { Pseudomonas }\end{array}$ & 36 & 3.5 \\
\hline 13 & 50 & $\mathrm{~F}$ & 49.8 & $\begin{array}{l}\text { Darunavir, emtricitabine, tenofovir, chloroquine, hy- } \\
\text { droxychloroquine, Ciproxin }\end{array}$ & $\begin{array}{l}\text { HIV, Enterobacter } \\
\text { aerogenes }\end{array}$ & 52 & 24 \\
\hline 14 & 58 & M & 31.0 & Ciprofloxacin, vancomycin & B. diastonis & 42 & 9 \\
\hline
\end{tabular}

BMI, body mass index; F, female; HCV, hepatitis C virus; HIV, human immunodeficiency virus; HSV1, herpes simplex virus 1; M, male.

Table 2. Hepatic biological data of a series of 14 patients deceased due to COVID-19 infection

\begin{tabular}{llc}
\hline $\begin{array}{l}\text { Patient } \\
\text { No. }\end{array}$ & $\begin{array}{l}\text { AST/ALT/GGT at the } \\
\text { moment of admission, } \\
\text { U/L }\end{array}$ & $\begin{array}{l}\text { AST/ALT/GGT } \\
\text { at the moment of } \\
\text { death, U/L }\end{array}$ \\
\hline 1 & $98 / 35 / 28$ & $81 / 64 / 32$ \\
2 & $17 / 10 / 15$ & $9,850 / 2,500 / 290$ \\
3 & $35 / 24 / 54$ & $88 / 75 / 103$ \\
4 & $24 / 17 / 22$ & $15 / 10 / 24$ \\
5 & $77 / 46 / 108$ & $43 / 46 / 105$ \\
6 & $188 / 62 / 36$ & $169 / 71 / 84$ \\
7 & $76 / 58 / 179$ & $24,176 / 7,245 / 180$ \\
8 & $77 / 39 / 25$ & $1,834 / 1,777 / 160$ \\
9 & $15 / 8 / 10$ & $50 / 18 / 52$ \\
10 & $15 / 7 / 126$ & $44 / 24 / 44$ \\
11 & $36 / 11 / 18$ & $37 / 15 / 33$ \\
12 & $38 / 27 / 33$ & $39 / 22 / 64$ \\
13 & $40 / 23 / 40$ & $77 / 46 / 503$ \\
14 & $15 / 58 / 22$ & $43 / 46 / 84$ \\
\hline
\end{tabular}

AST, aspartate amino transferase; ALT, alanine amino transferase; GGT, gamma glutamyl transferase.
The median length of hospital stay before death was 23.7 days (range 5-52 days).

The median time from death to autopsy was $20.2 \mathrm{~h}$ (range 2.5 to $73 \mathrm{~h}$ ).

\section{Histopathological Data of the Liver Examination}

The median liver weight was $1,987.85 \mathrm{~g}$ (range 1,2803,220 g).

Macroscopically, 8 livers (57\%) appeared pale and yellowish upon sectioning, and $6(42 \%)$ had a nutmeg appearance. Two livers (14\%) had an indurated consistency and appeared slightly irregular on the surface. The liver of patient 5 harbored an indurated, whitish nodule which was diagnosed as a well-differentiated hepatocellular carcinoma, not previously detected. Finally, only 1 liver presented with no macroscopic particularities.

Microscopically, we assessed the presence of necrosis, steatosis, lobular inflammation, portal inflammation, fibrosis, canalicular proliferation, hemosiderin, and glycogen. These results are shown in Table 3. 
Table 3. Histopathological findings in the liver of a series of 14 patients deceased due to COVID-19 infection

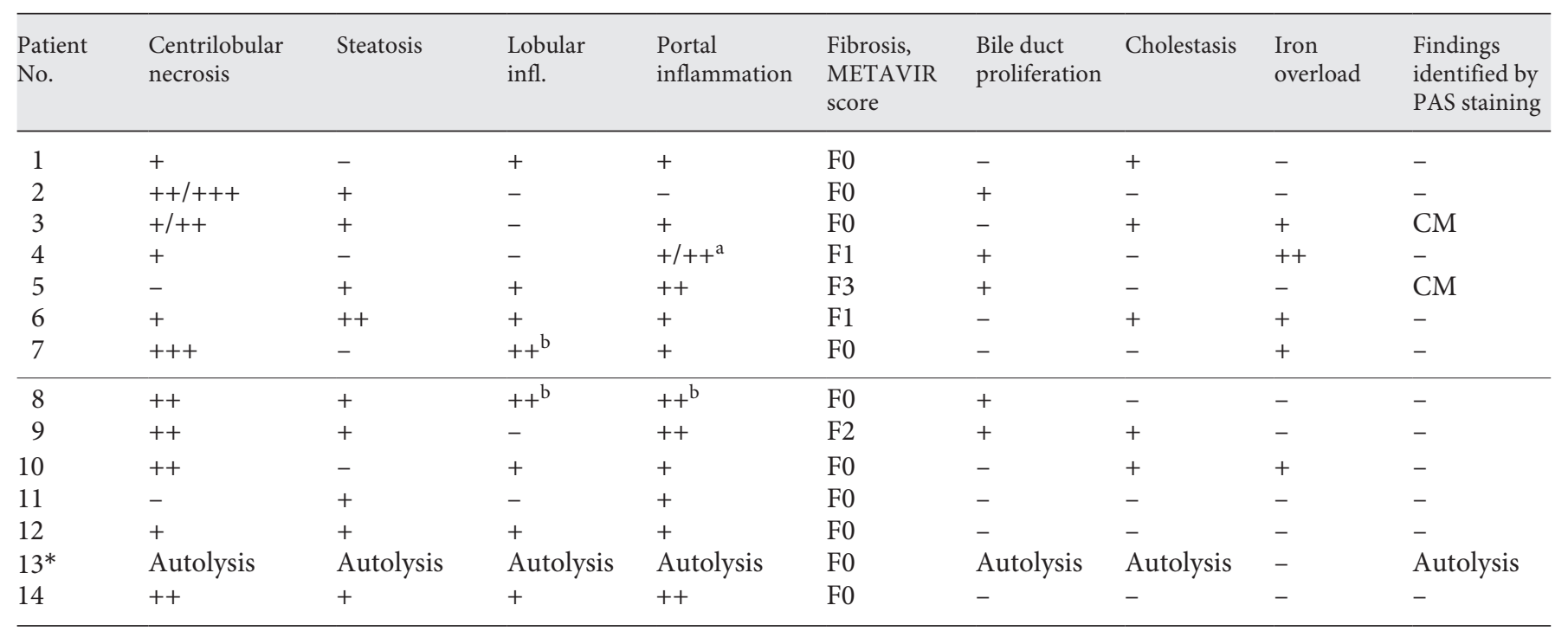

CM, ceroid macrophages. - , absent; + , mild; ++ , moderate; +++ , severe. ${ }^{*}$ We were unable to reliably evaluate the liver of patient 13 due to the presence of extensive autolysis. ${ }^{a}$ Prominent eosinophilic infiltrate. ${ }^{b}$ Prominent neurophilic infiltrate.

Two cases (14\%) showed no central lobular necrosis, while the other cases all demonstrated discrete or moderate necrosis in zone 3 , and sometimes in zone 2. One case presented with severe central lobular necrosis. Steatosis was present in 8 cases (57\%) and was assessed as discrete (5-33\%) or moderate (33-66\%) (Fig. 1).

Lobular and portal inflammation was present in 12 cases (86\%) (Fig. 1). Notably, 2 cases had a mixed infiltration with neutrophils, and 1 case (patient 4) had a predominantly eosinophilic infiltrate in the portal region.

Fibrosis was generally absent or discrete (F1, according to the Metavir score), with the exception of the patient already known to have NASH.

Five specimens (36\%) presented with a discrete iron overload, and 2 contained ceroid macrophages.

Cholestasis was assessed using HE staining and CK7 immunochemistry, and it was observed in 5 cases, while a discrete canalicular proliferation was found in a further 5 cases $(36 \%)$ (Fig. 1). Vascular thrombi and endothelialitis were not observed.

\section{Discussion}

The incidence of COVID-19 infection was first recorded in December 2019 in China and quickly proved to be a potentially severe, pneumonia-like infection [2022].

The Liver in COVID-19-Related Death
Successive studies have shown that other organs are involved in the pathogenesis of SARS-CoV-2, including the kidneys [13, 14, 23], the brain [24], and the cardiovascular system [25].

This multi-organ involvement seems to imply the participation of ACE2 receptors as a pathway for SARS$\mathrm{CoV}-2$ to enter the cells $[26,27]$. Since ACE2 is expressed in the liver, and especially in the bile duct epithelial cells [28], the liver may be a potential target organ for COVID-19. The results of the histological analyses carried out on our series of 14 cases do not, however, demonstrate the existence of a pattern specific to liver damage by SARS-CoV- 2 .

We mainly observed centrilobular necrosis, generally discreet lobular or portal inflammation and, in 5 cases (36\%), discrete proliferation of the bile ducts. We hypothesize that these observations were not specific for COVID-19, and that they might indicate existing hepatic comorbidities.

We do not believe these lesions are attributed to direct action of the COVID-19 infection and propose several mechanisms that may be responsible.

The hypothesis of direct action of the virus on hepatic cells has been raised by Li and Xiao [17]. In particular, they describe foci of periportal and centrilobular necrosis without significant inflammation, compatible with acute liver damage. In our series, we observed that the necrosis was essentially centrilobular and discrete or moderate in 

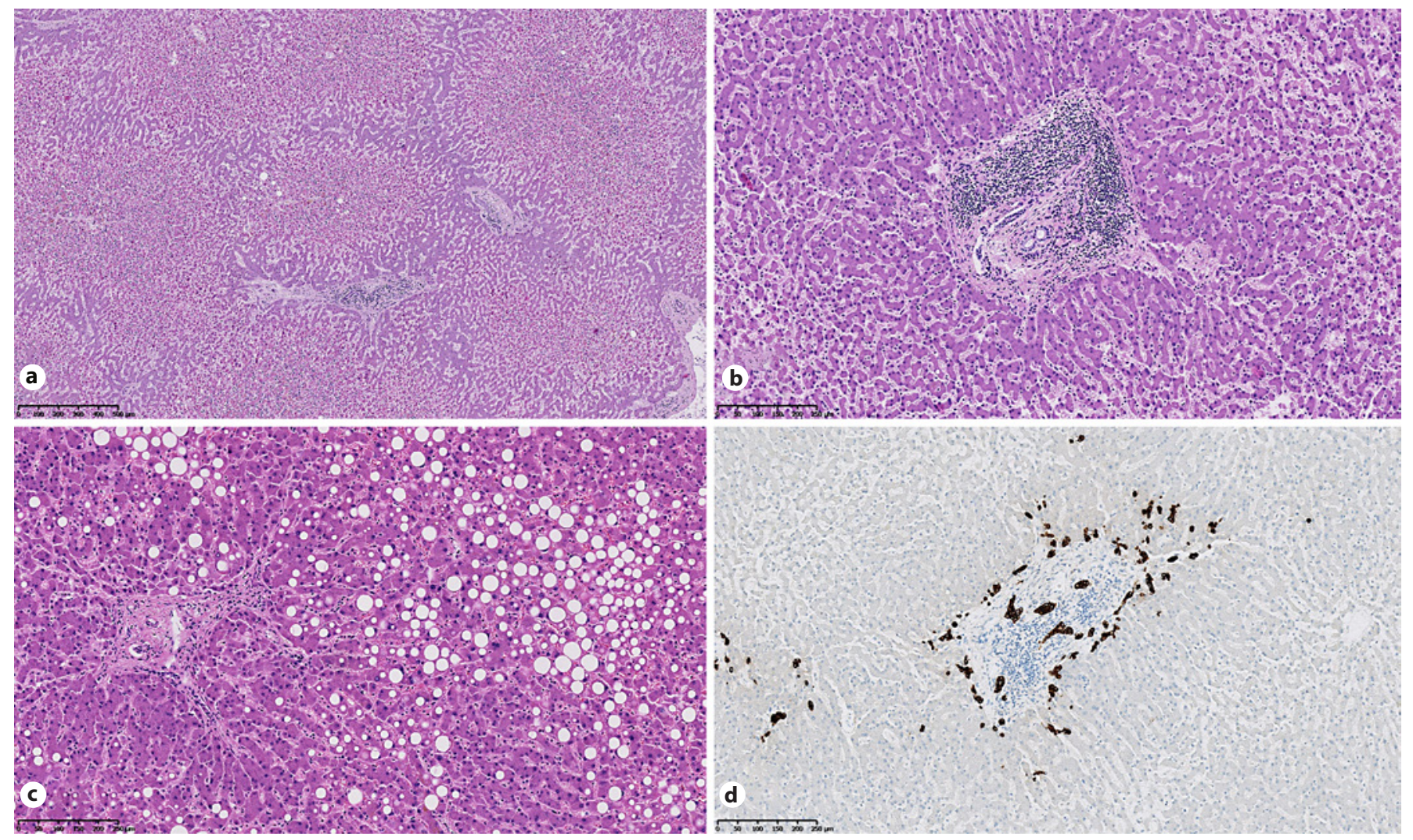

Fig. 1. Histological features of liver in SARS-CoV-2 infection. HE staining shows centrilobular necrosis (a), portal inflammation (b), and steatosis (c). d CK7 immunostaining highlights bile duct proliferation.

extent. Only 1 case (patient 7) showed severe necrosis. This necrosis was systematically associated with a discreet portal or lobular inflammation, and this pattern seems more compatible with a hypoxic origin [29] in patients with severe pneumonia, and may be the result of a long period of hospitalization in the intensive care unit (mean duration 23.7 days). In addition, ACE2 receptors are more abundant in the bile ducts [17]. If the liver damage was due to the direct action of the SARS-CoV-2 virus, we would expect to observe a major cholestasis and a greater reactive biliary proliferation. In our series, the biliary system showed only limited inflammation. Furthermore, the presence of limited lobular and portal inflammation observed in our series does not seem to implicate a direct action of the virus on the liver. Indeed, while these patients presented with a severe infection with hypoxemic pneumonia, which led to their death, liver inflammation remained very moderate, or even limited at most. We cannot prove an association between liver inflammation and acute bacterial infection. Most patients presented with a concomitant superinfection of one or more pathogens, but only 2 liver specimens (patients 7 and 8) contained a mixed inflammation with neutrophils, indicating a more active, or acute type of hepatic inflammation.

Of note was that only 1 liver specimen (patient 4) presented with an inflammation rich in eosinophils. Patient 4 was the only patient in our series to be treated with amiodarone. Amiodarone-related lung injury has been described before, but we do not have sufficient evidence to support amiodarone-related eosinophilic hepatic inflammation [30]. Although we consider this an interesting observation, more research on this topic is required.

Drug toxicity may also have played a role in the development of liver damage. Zone 3 of the liver is preferentially injured in the event of toxic damage. However, most of the cases in this study were treated with hydroxychloroquine and several antibiotics. These drugs have variable, but generally low, liver toxicity when normal dosages are adhered to. The hypoxia caused by severe lung damage may, however, have weakened the resistance of hepatocytes to toxic damage.
Schmit/Lelotte/Vanhaebost/Horsmans/ Van Bockstal/Baldin 
Hepatic drug toxicity is generally characterized by eosinophilic inflammation and a slight degree of fibrosis. These modifications were seen in 1 patient (patient 4). It is therefore possible that in some cases drug and antibiotics toxicity may have participated in the liver damage described here, as suggested by Li and Xiao [17], although we do not have objective elements allowing to confirm this hypothesis, except in patient 4 .

Liver steatosis was generally limited in extent, and moderate in only 1 case (patient 6 ), who had a BMI of 39.8 $\mathrm{kg} / \mathrm{m}^{2}$. It would appear that the steatosis observed in this case had a metabolic origin and was not directly related to the COVID-19 infection. The average BMI of the patients in our series was $32 \mathrm{~kg} / \mathrm{m}^{2}$. In addition, the prevalence of non-alcoholic fatty liver disease (NAFLD) in the general population varies between 20 and $>50 \%$ [31]. It is, therefore, not surprising to find a high prevalence of NAFLD in an autopsy series of patients deceased after COVID-19 infection. There is thus insufficient evidence to favor an association of COVID-19 infection and the development of fatty liver disease.

Finally, hepatic fibrosis was rare in our case series. A METAVIR F3 stage of fibrosis was observed in only 1 patient, and this was presumed to be secondary to NASH. One patient with HCV infection presented with moderate (F2) fibrosis. Fibrosis is a condition that generally develops after a chronic hepatic inflammation of various origins. It is therefore unlikely that hepatic fibrosis develops at the acute stage of COVID-19 infection.

In general, the histological changes observed in this series can be explained by the clinical history of these patients.

Furthermore, we observed no significant augmentation of the hepatic enzymes during hospitalization. This absence of biological signs of liver damage in most of the patients is not compatible with direct action of the COVID-19 infection.

\section{Conclusion}

Histological liver changes were observed in all 14 patients of this autopsy series. Central lobular necrosis (zone 3, and in some instances, zone 2) limited to moderate lobular and portal inflammation, was the most frequently observed histopathological change. Nonetheless, we hypothesize that these changes were not the result of direct damage by the SARS-CoV-2 virus. A combination of hypoxia caused by severe pulmonary disease and drug toxicity seem to be a more likely cause of hepatic damage in deceased COVID-19 patients.
The hepatic fibrosis and steatosis that we observed also appeared to be related to the underlying (often already known) liver disease, and not a direct result of the COVID-19 infection.

At present, there is no evidence for a hepatic histopathological pattern specific to SARS-CoV-2 infection. This observation seems to be consistent with the fact that isolated acute liver failure has thus far not been described in patients with COVID-19.

\section{Statement of Ethics}

This study was approved by the ethics committee (comité d'éthique hospitalo-facultaire, Saint-Luc University Hospital/ UCLouvain, 2020/265).

\section{Conflict of Interest Statement}

The authors declare no conflict of interest.

\section{Funding Sources}

This research did not receive any specific grant from funding agencies in the public, commercial, or not-for-profit sectors.

\section{Author Contributions}

Conceptualization: G.S., P.B., and Y.H.; methodology: G.S., P.B., M.V.B., and Y.H.; autopsies: G.S., J.L., and J.V.; histological examination: G.S., P.B., and J.L.; writing: G.S.; supervision: P.B. and M.V.B.

\section{References}

$$
\begin{aligned}
& 1 \text { Chen ZL, Zhang Q, Lu Y, Guo ZM, Zhang X, } \\
& \text { Zhang WJ, et al. Distribution of the CO- } \\
& \text { VID-19 epidemic and correlation with popu- } \\
& \text { lation emigration from Wuhan, China. Chin } \\
& \text { Med J. 2020 May;133(9):1044-1050. } \\
& 2 \text { Carinci F. Covid-19: preparedness, decentral- } \\
& \text { isation, and the hunt for patient zero. BMJ. } \\
& 2020 \text { Feb;28:368. } \\
& 3 \text { https://www.sciensano.be/en } \\
& 4 \text { Salerno M, Sessa F, Piscopo A, Montana A, } \\
& \text { Torrisi M, Patanè F, et al. No autopsies on } \\
& \text { COVID-19 deaths: a missed opportunity and } \\
& \text { the lockdown of science. J Clin Med. } 2020 \\
& \text { May;9(5):1472. } \\
& 5 \text { De Cock KM, Zielinski-Gutiérrez E, Lucas SB. } \\
& \text { Learning from the Dead. N Engl J Med. } 2019 \\
& \text { Nov;381(20):1889-91. }
\end{aligned}
$$


6 Von Stillfried S, Bulow RD, Röhrig R, Knüchel-Clarke R, Boor P; DeRegCOVID. Autopsy registry can facilitate COVID-19 research. EMBO Mol Med. 2020 Aug; 12(8):e12885. https://doi.org/10.15252/ emmm.202012885.

$7 \mathrm{Xu} \mathrm{Z,} \mathrm{Shi} \mathrm{L,} \mathrm{Wang} \mathrm{Y,} \mathrm{Zhang} \mathrm{J,} \mathrm{Huang} \mathrm{L,}$ Zhang C, et al. Pathological findings of COVID-19 associated with acute respiratory distress syndrome. Lancet Respir Med. 2020 Apr; 8(4):420-2.

8 Barton LM, Duval EJ, Stroberg E, Ghosh S, Mukhopadhyay S. COVID-19 Autopsies, Oklahoma, USA. Am J Clin Pathol. 2020 May; 153(6):725-33.

9 Wichmann D, Sperhake JP, Lütgehetmann M, Steurer S, Edler C, Heinemann A, et al. Autopsy Findings and Venous Thromboembolism in Patients With COVID-19: A Prospective Cohort Study. Ann Intern Med. 2020 Aug;173(4):268-77.

10 Tian S, Xiong Y, Liu H, Niu L, Guo J, Liao M, et al. Pathological study of the 2019 novel coronavirus disease (COVID-19) through postmortem core biopsies. Mod Pathol. 2020 Jun;33(6):1007-14.

11 Menter T, Haslbauer JD, Nienhold R, Savic S, Hopfer H, Deigendesch N, et al. Postmortem examination of COVID-19 patients reveals diffuse alveolar damage with severe capillary congestion and variegated findings in lungs and other organs suggesting vascular dysfunction. Histopathology. 2020 May;77(2): 198-209.

12 Hanley B, Lucas SB, Youd E, Swift B, Osborn M. Autopsy in suspected COVID-19 cases. J Clin Pathol. 2020 May;73(5):239-42.

13 Su H, Yang M, Wan C, Yi LX, Tang F, Zhu $\mathrm{HY}$, et al. Renal histopathological analysis of 26 postmortem findings of patients with $\mathrm{CO}$ VID-19 in China. Kidney Int. 2020 Jul;98(1): 219-27.

14 Naicker S, Yang CW, Hwang SJ, Liu BC, Chen JH, Jha V. The Novel Coronavirus 2019 epidemic and kidneys. Kidney Int. 2020 May; 97(5):824-8.
15 Guan WJ, Ni ZY, Hu Y, Liang WH, Ou CQ, He JX, et al.; China Medical Treatment Expert Group for Covid-19. Clinical characteristics of coronavirus disease 2019 in China. N Engl J Med. 2020 Apr;382(18):1708-20.

16 Yang X, Yu Y, Xu J, Shu H, Xia J, Liu H, et al. Clinical course and outcomes of critically ill patients with SARS-CoV-2 pneumonia in Wuhan, China: a single-centered, retrospective, observational study. Lancet Respir Med. 2020 May;8(5):475-81.

$17 \mathrm{Li} \mathrm{Y,} \mathrm{Xiao} \mathrm{SY.} \mathrm{Hepatic} \mathrm{involvement} \mathrm{in} \mathrm{CO-}$ VID-19 patients: Pathology, pathogenesis, and clinical implications [review]. J Med Virol. 2020 May;92(9):1-4.

18 Santurro A, Scopetti M, D'Errico S, Fineschi V. A technical report from the Italian SARSCoV-2 outbreak. Postmortem sampling and autopsy investigation in cases of suspected or probable COVID-19. Forensic Sci Med Pathol. 2020 Sep;16(3):471-6.

19 Xue Y, Lai L, Liu C, Niu Y, Zhao J. Perspectives on the death investigation during the COVID-19 pandemic. Forensic Sci Int. 2020 Apr;2:126-8.

20 Zhu N, Zhang D, Wang W, Li X, Yang B, Song J, et al.; China Novel Coronavirus Investigating and Research Team. A novel coronavirus from patients with pneumonia in China, 2019. N Engl J Med. 2020 Feb;382(8):727-33.

21 Chen N, Zhou M, Dong X, Qu J, Gong F, Han $\mathrm{Y}$, et al. Epidemiological and clinical characteristics of 99 cases of 2019 novel coronavirus pneumonia in Wuhan, China: a descriptive study. Lancet. 2020 Feb;395(10223):507-13.

22 Chan JF, Yuan S, Kok KH, To KK, Chu H, Yang J, et al. A familial cluster of pneumonia associated with the 2019 novel coronavirus indicating person-to-person transmission: a study of a family cluster. Lancet. 2020 Feb; 395(10223):514-23.
23 Staico MF, Zaffanello M, Di Pietro G, Fanos V, Marcialis MA. The kidney in COVID-19: protagonist or figurant? Panminerva Med. 2020 May.

24 Reichard RR, Kashani KB, Boire NA, Constantopoulos E, Guo Y, Lucchinetti CF. Neuropathology of COVID-19: a spectrum of vascular and acute disseminated encephalomyelitis (ADEM)-like pathology. Acta Neuropathol. 2020 Jul;140(1):1-6.

25 Guzik TJ, Mohiddin SA, Dimarco A, Patel V, Savvatis K, Marelli-Berg FM, et al. COVID-19 and the cardiovascular system: implications for risk assessment, diagnosis, and treatment options. Cardiovasc Res. 2020 Aug;116(10): 1666-87.

26 Groß S, Jahn C, Cushman S, Bär C, Thum T. SARS-CoV-2 receptor ACE2-dependent implications on the cardiovascular system: from basic science to clinical implications. J Mol Cell Cardiol. 2020 Jul;144:47-53.

27 Varga Z, Flammer AJ, Steiger P, Haberecker $\mathrm{M}$, Andermatt R, Zinkernagel AS, et al. Endothelial cell infection and endotheliitis in COVID-19. Lancet. 2020 May;395(10234):14178.

28 Chai X, Hu L, Zhang Y, et al. Specific ACE2 expression in cholangiocytes may cause liver damage after 2019-nCoV infection. bioRxiv. 2020. Available from https://www.biorxiv. org/content/10.1101/2020.02.03.931766v1. full https://doi.org/10.1101/2020.02.03. 931766.

29 Ebert EC. Hypoxic liver injury. Mayo Clin Proc. 2006 Sep;81(9):1232-6.

30 Alqaid A, Baskaran G, Dougherty C. Amiodarone-induced lung injury with bilateral lung pneumonitis and peripheral eosinophilia. Am J Ther. 2016 Jul-Aug;23(4):e1121-3.

31 Vernon G, Baranova A, Younossi ZM. Systematic review: the epidemiology and natural history of non-alcoholic fatty liver disease and non-alcoholic steatohepatitis in adults. Aliment Pharmacol Ther. 2011 Aug;34(3):27485. 